\title{
The Future of USP Monographs for PET Drugs
}

Sally Schwarz ${ }^{1,2}$, Jeffrey Norenberg ${ }^{2,3}$, Marc Berridge ${ }^{2,4}$, Stephen Dragotakes ${ }^{2,5}$, Joseph Hung ${ }^{2,6}$, Jeanne Link ${ }^{2,7}$, N. Scott Mason 2,8 , Steve Mattmuller ${ }^{2}$, Richard A. Nickel ${ }^{2}$, Alan Packard ${ }^{2,9}$, Justin Paolino ${ }^{2,10}$, Neil Petry 2,11 , James Ponto ${ }^{2,12}$, Timothy M. Quinton², Katherine L. Seifert ${ }^{2,13}$, Dennis Swanson ${ }^{2,14}$, Ronald E. Weiner ${ }^{2,15}$, and Steven Zigler ${ }^{2}, 16$

${ }^{1}$ Washington University School of Medicine, St. Louis, Missouri; ${ }^{2}$ Committee on Pharmacopeia, Society of Nuclear Medicine and Molecular Imaging, Reston, Virginia; ${ }^{3}$ University of New Mexico Health Sciences Center, Albuquerque, New Mexico; ${ }^{4} 3 D$ Imaging, LLC, University of Arkansas for Medical Sciences, Little Rock, Arkansas; ${ }^{5}$ Beth Israel Deaconess Medical Center, Boston, Massachusetts; ${ }^{6}$ Mayo Clinic, Rochester, Minnesota; ${ }^{7}$ University of Washington, Seattle, Washington; ${ }^{8}$ Department of Radiology, University of Pittsburgh, Pittsburgh, Pennsyvania; ${ }^{9}$ Boston Children's Hospital and Harvard Medical School, Boston, Massachusetts; ${ }^{10}$ Brigham and Women's Hospital, Boston, Massachusetts; ${ }^{11}$ Duke University Medical Center, Durham, North Carolina; ${ }^{12}$ University of Iowa, Iowa City, Iowa; ${ }^{13}$ Seifert and Associates, Los Angeles, California; ${ }^{14}$ University of Pittsburgh School of Pharmacy, Pittsburgh, Pennsylvania; ${ }^{15}$ Ron Weiner Services, Sherman Oaks, California; and ${ }^{16}$ Siemens PETNET Solutions, Knoxville, Tennessee

\section{$\mathbf{S}$} (FDAMA) required that PET drugs be prepared according to U.S. Pharmacopeia (USP) compounding standards and PET drug monographs until the Food and Drug Administration (FDA) established appropriate approval processes and good manufacturing practice (GMP) regulations specific to these drug products. With the FDA's final enactment of its FDAMA commitments on June 12, 2012, the provisions of section 121 are no longer in effect. This created an unprecedented situation wherein a long-standing regulatory pathway for PET drugs was eliminated. The objectives of this article are 3-fold: to describe FDAMA and the role of USP monographs, to describe the impact of potential changes to the role of USP monographs for PET drugs after the sunset of FDAMA, and to describe recommendations from the Society of Nuclear Medicine and Molecular Imaging (SNMMI) Committee on Pharmacopeia for the future of USP monographs for PET drugs.

\section{THE USP MONOGRAPHS AND FDAMA, SECTION 121}

The USP is a compendium of drug quality standards. USP drug standards (i.e., monographs) are typically developed after FDA approval of the drug product for commercial marketing and are based on information and data supplied to the USP by the responsible pharmaceutical company. The U.S. FDA recognizes the USP as an official compendium and may enforce compliance with USP standards under the adulteration and misbranding provisions of the Federal Food, Drug,

Received Oct. 1, 2012; revision accepted Oct. 5, 2012.

For correspondence or reprints contact: Sally Schwarz, Washington University School of Medicine, 510 S. Kingshighway, St. Louis, MO 63110.

E-mail: schwarzs@wustl.edu

Published online Dec. 21, 2012.

COPYRIGHT (C 2013 by the Society of Nuclear Medicine and Molecular Imaging, Inc.

DOI: $10.2967 /$ jnumed.112.115089 and Cosmetic Act. These provisions extend broad authority to the FDA to prevent the marketing of drugs that do not meet USP standards. Publication of a USP monograph for a drug product does not mean, however, that all drug products that meet USP standards are FDA-approved for commercial marketing. Rather, the FDA approves marketing applications from pharmaceutical companies or other entities in the form of a New Drug Application (NDA) or Abbreviated New Drug Application (ANDA) for the drug product. Also, because the existence of a USP monograph does not, by itself, confer FDA-approval status, reimbursement decisions related to a drug product are not based on whether a USP monograph is in place for that drug product.

Section 121 of FDAMA enabled the clinical use (i.e., use for routine patient care) of PET drugs that were compounded "in conformity with the PET compounding standards and the official monographs of the United States Pharmacopoeia..." until such time that the FDA established approval processes and GMPs specific to PET drugs (1). Likewise, FDAMA specified that the preparation of PET drugs being evaluated or used under an Investigational New Drug (IND) application (title 21 of Code of Federal Regulations part 312 [21 CFR 312]) or the Radioactive Drug Research Committee (RDRC) regulatory pathway (21 CFR 361) must be in conformance with USP General Chapter < 823> ("PET Drugs for Compounding, Investigational, and Research Uses") and the USP monograph for the PET drug, if such was in existence. In this manner, FDAMA established a unique role for the USP compounding standards and monographs for PET drugs in that USP criteria substituted for compliance with the FDA's standard drug approval processes and the FDA's GMP standards for traditional drug products (21 CFR 211).

With the FDA's final enactment of its FDAMA commitments on June 12, 2012, the provisions of section 121 of FDAMA are no longer in effect. This created an unprecedented situation wherein a long-standing regulatory pathway is now eliminated for PET drugs. After this date: 
1. PET drugs intended for clinical use must be produced according to a submitted NDA/ANDA and PET GMP standards (21 CFR 212). This applies to commercially distributed PET drugs, as well as to those prepared at medical institutions for internal use.

2. Nonapproved PET drugs intended for clinical research purposes must be prepared in accordance with the PET GMPs or with USP General Chapter $<823>$. In addition, these PET drugs must be subject to either approval by an RDRC (21 CFR 361) or FDA acceptance of an IND application (21 CFR 312). Note that clinical research studies directed at using or evaluating FDA-approved PET drugs for off-label indications may or may not be subject to the submission of an IND application (see IND exemption criteria at 21 CFR 312.2).

USP General Chapter $<823>$ requires compliance with USP standards if a USP monograph exists for a PET drug; however, a monograph is not a requirement for the production of a PET drug under this USP General Chapter. In addition, a USP monograph is not required for PET drugs produced under an approved NDA/ANDA or under evaluation according to an FDA-accepted IND application. Since the regulatory approval pathways for PET drugs in the postFDAMA era are independent of the existence of a USP monograph, a reevaluation of the role of USP monographs for these drugs is warranted.

\section{THE USP MONOGRAPH PROCESS AND ITS FUTURE APPLICATION TO PET DRUGS}

As previously stated, the USP is a compendium of drug standards (i.e., monographs). USP monographs are typically developed some time after FDA approval of the drug product for commercial marketing. The monographs are routinely sponsored by the pharmaceutical company in possession of an approved NDA or ANDA for the product of interest. The sponsor provides supporting data from its approved application, including method validation data for the analytic methods used for the drug product. This information is necessary either to create a new monograph or to revise an existing monograph. The sponsor also provides samples of the appropriate reference standards to the USP to support the analytic methods used for the drug. The USP scientific staff and expert volunteers review the information from the sponsor, conduct laboratory tests if necessary, and publish the new or revised monograph in the Pharmacopeial Forum for public comment. On the basis of the comments received through the Pharmacopeial Forum, the USP staff and expert volunteers take appropriate action to finalize the monograph. In this manner, the information from the sponsor and public comments provide the foundation for the standards that appear in USP monographs. The USP Web site (www.usp.org) describes the monograph development process in more detail.

During the early evolution of PET and before the involvement of the FDA, there were no public standards for the preparation (i.e., compounding) of PET drugs that were used for clinical or research purposes. This lack led the USP to develop PET drug compounding standards and monographs. The first USP monograph for a PET drug was published in 1989 (2). This monograph described quality standards and analytic methods for ${ }^{18} \mathrm{~F}$-fludeoxyglucose injection. More monographs were published for various PET drugs throughout the 1990s, and the total number of USP monographs for PET drugs now stands at 12 . The quality standards and analytic methods included in these monographs were provided to the USP by various academic sponsors. The supporting data for these monographs may not have included suitable validation data to support the analytic methods. In addition, reference standards may not have been provided to the USP. Of the 12 PET drugs with a USP monograph, 8 have limited commercial application and are not currently described in an approved NDA or ANDA. These products are described in Table 1. The remaining 4 PET drugs with a USP monograph have been commercially distributed and are described in an approved NDA or ANDA. These products, approvals, and sponsors are described in Table 2. The USP will work directly with the NDA and ANDA sponsors to manage USP monographs for the products listed in Table 2. Since this is a typical process for the USP, it will not be discussed further.

With the sunset of the provisions in section 121 of FDAMA, the PET community must consider changes to the role of USP monographs for the non-FDA-approved PET drugs listed in Table 1. These considerations must address the fact that method validation data and reference standards may not exist for some of the PET drug monographs. In some cases, the analytic method may even be outdated or may use chromatographic columns that are no longer commercially available. There are 3 potential approaches for managing the future of these PET drug monographs.

The first approach is to leave the USP monographs for the PET drugs listed in Table 1 as they are currently written. Compared with traditional drug products, this creates the unusual situation wherein USP monographs exist for drugs that are not FDA-approved. For PET drugs prepared in accordance with USP General Chapter

TABLE 1

PET Drugs with a USP Monograph but Not Approved by the FDA

PET drug

${ }^{18} \mathrm{~F}$-fluorodopa injection
${ }^{11} \mathrm{C}$-flumazenil injection
${ }^{11} \mathrm{C}$-methionine injection
${ }^{11} \mathrm{C}$-raclopride injection
${ }^{11} \mathrm{C}$-sodium acetate injection
${ }^{11} \mathrm{C}$-carbon monoxide injection
${ }^{11} \mathrm{C}$-mespiperone injection
${ }^{15} \mathrm{O}$-water injection


TABLE 2

PET Drugs with a USP Monograph and an Approved NDA or ANDA (7)

\begin{tabular}{|c|c|c|c|c|}
\hline PET Drug & Application number & Holder & Approval date & Current status \\
\hline${ }^{13} \mathrm{~N}-$ ammonia injection & NDA 22-119 & Feinstein Institute & August 23, 2007 & Active \\
\hline \multirow[t]{4}{*}{${ }^{18} \mathrm{~F}$-fludeoxyglucose injection } & NDA 20-306 & Downstate Clinical PET Center & August 19, 1994 & Discontinued \\
\hline & NDA 21-768 & Weill Medical College & August 4, 2004 & Active \\
\hline & NDA 21-870 & Feinstein Institute & August 19, 2005 & Active \\
\hline & ANDA 79-086 & PETNET Solutions & February 25, 2011 & Active \\
\hline \multirow[t]{2}{*}{${ }^{18} \mathrm{~F}$-sodium fluoride injection } & NDA 17-042 & GE Healthcare & February 24, 1972 & Discontinued \\
\hline & NDA 22-494 & National Cancer Institute & January 26, 2011 & Discontinued \\
\hline${ }^{89} \mathrm{Rb}$ rubidium chloride injection & NDA $19-414$ & Bracco & December 29, 1989 & Active \\
\hline
\end{tabular}

$<823>$, compliance with the respective USP monograph would be required for those PET drugs with a USP monograph. If it is not possible to comply with an existing USP monograph, institutions involved in approving the respective clinical investigation under the authority of an RDRC (21 CFR 361) would be required to submit an IND application. Under an IND application, the FDA may exert enforcement discretion with regard to whether compliance with the USP monograph is required. However, RDRCs do not have the authority to exert such enforcement discretion. Thus, the existence of USP monographs for nonapproved PET drugs limits the flexibility of RDRCs regarding production processes and analytic methods for these PET drugs and can place restrictions on the RDRC's ability to approve a clinical investigation. In addition, since reference standards may not exist and the analytic methods may not be validated for some PET drug monographs, the potential exists for erroneous analytic methods. For these reasons, the do-nothing scenario does not seem to be a viable option.

The second approach is to revise the USP monographs in Table 1 . The revision process would address the development of appropriate validation data and the correction of erroneous or obsolete methods. The development of the appropriate reference standards should also be included in the revision process for these monographs. Similar to the first approach, this approach perpetuates the current, nonstandard situation in which USP monographs exist for drugs that are not FDA-approved and limits the flexibility of RDRCs and IND holders. The second approach requires a sponsor (or group of sponsors) from the PET community who must petition the USP to begin the revision process and provide the required data and reference standards to support the revision. The sponsor (or group of sponsors) would also be required to maintain the monograph on an ongoing basis in the event of future changes necessitated by new regulations, USP requirements, or obsolescence. USP would maintain the monographs in Table 1 as official, enforceable monographs.

The third approach is to eliminate the existing monographs for the PET drugs listed in Table 1. In this case, the USP would maintain monographs only for PET drugs that are FDA-approved. This approach provides RDRCs and
IND holders with more flexibility for the PET drugs listed in Table 1 since production processes and analytic methods may be described and justified in the IND or RDRC application, eliminating the need to follow prescribed methods in the USP. Institutions would be required to develop method validation data to support their IND or RDRC applications, but validation data at early development stages is typically less rigorous than that required for FDA-approved products $(3,4)$. The third approach does not require the identification of a sponsor (or group of sponsors) from the PET community to support the monographs for the PET drugs in Table 1. Finally, this approach places the PET monographs in a position consistent with monographs for traditional drugs. To achieve this approach, the PET community must petition the USP to eliminate the monographs in Table 1. In the future, if a sponsor is interested in gaining FDA approval of a drug in Table 1 with a deleted monograph, a new monograph for that drug could be developed and submitted to the USP pursuant to existing monograph submission guidelines.

Regardless of the scenario adopted for the PET drug monographs in Table 1, it is clear that the submission of new or revised monographs for PET drugs in the post-FDAMA era must be in accordance with current USP requirements, including the submission of the appropriate reference standards and validation data for analytic methods (e.g., accuracy, precision, sensitivity, and linearity) (5).

\section{USP MONOGRAPHS AND REIMBURSEMENT FOR INVESTIGATIONAL PET DRUGS}

The change in the regulatory status of the PET drugs in Table 1 may also have implications in limited instances in which imaging procedures that use these products are reimbursed. Medicare reimbursement for all PET drugs is limited under the national exclusionary ruling by the Center for Medicare and Medicaid Services. This applies to all PET drugs before and after the sunset of section 121 of FDAMA. Since the PET drugs in Table 1 could be used for routine patient care before June 12, 2012, private payers have reimbursed for some procedures associated with these PET drugs. It is also possible that the USP monographs for these PET drugs have played an important role in establishing the safety of these products. The extent of the reimbursement for these products is not known. 
As of June 12, 2012, the PET drugs in Table 1 cannot continue to be applied for traditional clinical uses because NDAs or ANDAs do not exist for these products. Instead, these PET drugs are now subject to either an RDRC or an IND. This created an unusual situation wherein PET drugs that have been used clinically (and may have been reimbursed by private payers) are now categorized as "research" or "investigational." The FDA has recognized this situation and responded with the publication of a guidance document describing the use of expanded-access INDs to allow the continued clinical use of the PET drugs in Table 1 (6). It is possible that private payers may continue to reimburse for expanded-access IND drugs. To date, the presence of a USP monograph for the PET drug has been used as one basis for a payment decision (Denise Merlino, oral communication, August 2012). If the USP would remove the outdated monographs to an "Omitted Monograph" category, including the date of removal, payers might still be able to access the Omitted Monograph and could continue to use it as a basis for a payment decision.

\section{RECOMMENDATION Of SNMMI COMMITTEE ON PHARMACOPEIA}

The SNMMI Committee on Pharmacopeia recommends that the existing USP monographs for PET drugs listed in Table 1 should be eliminated or moved to an Omitted Monograph status. These recommendations are based on the following considerations:

- This approach is consistent with the development of USP monographs for traditional drug products.

- The current USP monographs for these PET drugs may incorporate analytic methods that have not been suitably validated or may no longer be viable to perform.

- Compliance with the current USP monographs for these PET drugs places certain limitations on the preparation of these agents. The inability to comply with these USP monographs can restrict the ability to approve respective clinical investigations under the RDRC (21 CFR 361) approval process.

- Revision of the current USP monographs for the nonapproved PET drugs requires the active initial and continuing involvement of members of the PET community. Such active involvement has historically not been forthcoming.

- For PET drugs listed in Table 1, any interested individual or group can sponsor revision (including supporting validation data and standards) and provide maintenance of the monograph.

- The Committee recommends that development of future USP monographs for PET drugs should be limited to those drugs described in an FDA-approved NDA.

The SNMMI Committee on Pharmacopeia is actively seeking input from the PET community regarding current and future USP monographs for PET drugs. Anyone interested in commenting can visit the USP Key Issue page at http://www.usp.org/usp-nf/key-issues/usp-nf-generalchapter-823. All comments will be considered before taking any formal action related to the current USP monographs.

\section{ACKNOWLEDGMENT}

This article was approved by the SNMMI Committee on Pharmacopeia.

\section{REFERENCES}

1. U.S. Food and Drug Administration. Food and Drug Administration Modernization Act of 1997: section 121. http://www.fda.gov/RegulatoryInformation/Legislation/ FederalFoodDrugandCosmeticActFDCAct/SignificantAmendmentstotheFDCAct/ FDAMA/FullTextofFDAMAlaw/default.htm\#SEC. 121. Published January 7 , 1997. Accessed November 29, 2012.

2. U.S. Pharmacopeial Convention. USP 22-NF 17, Fludeoxyglucose F 18 Injection. Rockville, MD: U.S. Pharmacopeial Convention; 1990:579-580.

3. Food and Drug Administration. Guidance for industry: CGMP for phase 1 investigational drugs. http://www.fda.gov/downloads/Drugs/GuidanceComplianceRegulatoryInformation/Guidances/ucm070273.pdf. Published July 2008. Accessed November 29, 2012.

4. Food and Drug Administration. Guidance for industry: analytical procedures and methods validation [draft]. http://www.fda.gov/downloads/Drugs/. ../Guidances/ UCM122858.pdf. Published August 2000. Accessed November 29, 2012.

5. U.S. Pharmacopeial Convention. USP 32-NF 27, Validation of Compendial Procedures $<1225>$. Rockville, MD: U.S. Pharmacopeial Convention; 2009: $1-33$.

6. Food and Drug Administration. Guidance: investigational new drug applications for positron emission tomography (PET) drugs [draft]. http://www.fda.gov/downloads/ Drugs/GuidanceComplianceRegulatoryInformation/Guidances/UCM291573.pdf. Published February 2012. Accessed November 29, 2012.

7. Food and Drug Administration. Orange book. http://www.accessdata.fda.gov/ scripts/cder/ob/default.cfm. Updated November 16, 2912. Accessed November $29,2012$. 